\title{
Effects of genistein supplementation on genome-wide DNA methylation and gene expression in patients with localized prostate cancer
}

\author{
BIRDAL BILIR ${ }^{1,5}$, NITYA V. SHARMA ${ }^{1}$, JEONGSEOK LEE ${ }^{1}$, BATO HAMMARSTROM ${ }^{2,7}$, \\ AUD SVINDLAND ${ }^{3,4}$, OMER KUCUK ${ }^{5,6}$ and CARLOS S. MORENO ${ }^{1,6}$ \\ ${ }^{1}$ Department of Pathology and Laboratory Medicine, Emory University, Atlanta, GA, USA; ${ }^{2}$ Department of Urology, \\ Institute of Cancer Research, Oslo University Hospital; ${ }^{3}$ Department of Clinical Medicine, University of Oslo; \\ ${ }^{4}$ Department of Pathology, Oslo University Hospital, Oslo, Norway; ${ }^{5}$ Department of Hematology \\ and Medical Oncology, and ${ }^{6}$ Winship Cancer Institute, Emory University, Atlanta, GA, USA
}

Received December 14, 2016; Accepted March 27, 2017

DOI: 10.3892/ijo.2017.4017

\begin{abstract}
Epidemiological studies have shown that dietary compounds have significant effects on prostate carcinogenesis. Among dietary agents, genistein, the major isoflavone in soybean, is of particular interest because high consumption of soy products has been associated with a low incidence of prostate cancer, suggesting a preventive role of genistein in prostate cancer. In spite of numerous studies to understand the effects of genistein on prostate cancer, the mechanisms of action have not been fully elucidated. We investigated the differences in methylation and gene expression levels of prostate specimens from a clinical trial of genistein supplementation prior to prostatectomy using Illumina HumanMethylation450 and Illumina HumanHT-12 v4 Expression BeadChip Microarrays. The present study was a randomized, placebo-controlled, double-blind clinical trial on Norwegian patients who received $30 \mathrm{mg}$ genistein or placebo capsules daily for 3-6 weeks before prostatectomy. Gene expression changes were validated by quantitative PCR (qPCR). Whole genome methylation and expression profiling identified differentially methylated sites and expressed genes between placebo and genistein groups. Differentially regulated genes were involved in developmental processes, stem cell markers, proliferation and transcriptional regulation. Enrichment analysis suggested overall reduction in
\end{abstract}

Correspondence to: Dr Carlos S. Moreno, Department of Pathology and Laboratory Medicine, Winship Cancer Institute, Emory University, Whitehead Research Building, Room 105J, 615 Michael Street, Atlanta, GA 30322, USA

E-mail: cmoreno@emory.edu

Present address: ${ }^{7}$ Department of Environmental and Occupational Medicine, Oslo University Hospital, Oslo, Norway

Key words: genistein, prostate cancer, DNA methylation, gene expression
MYC activity and increased PTEN activity in genistein-treated patients. These findings highlight the effects of genistein on global changes in gene expression in prostate cancer and its effects on molecular pathways involved in prostate tumorigenesis.

\section{Introduction}

Prostate cancer is the most commonly diagnosed malignancy and the second leading cause of cancer death among men in the United States. It is estimated that approximately 180,890 new cases of prostate cancer and 26,120 deaths from prostate cancer occurred in the USA in 2016 (1). The common risk factors for prostate cancer are age, race/ethnicity, geography, family history and lifestyle (2). Depending on the severity of the disease, current treatment options for prostate cancer include single or a combination of therapies such as active surveillance, surgery, radiation therapy, chemotherapy, hormone therapy or vaccines (3). Although these interventions have significantly improved the quality of life of the patients and the overall survival rates, effective treatment of prostate cancer is still limited due to the major challenges such as genetic heterogeneity, tumor recurrence ( $30 \%$ of the cases) and resistance to conventional chemotherapeutic drugs (4-6). Therefore, it is crucial to develop novel preventive and therapeutic strategies that have the potential to improve outcomes for prostate cancer patients.

Epidemiological studies have shown that there is a significant disparity in incidence and mortality rates of prostate cancer among different countries, with the highest rates in the USA and European countries and the lowest rates in Asian countries such as Japan and China $(7,8)$. This wide variability in the prostate cancer rates across countries suggests that several factors including genetic, epigenetic and environmental differences play a key role in the etiology of the disease. Notably, it has been shown that Asian immigrants in the USA have an increased incidence of prostate cancer compared to those individuals with the same genetic background who live in Asia, indicating that environmental factors, especially the 
diet, are major determinants of prostate cancer incidence (9). One of the remarkable dietary differences between Asian and Western countries is the amount of soy-based food consumption. Asian populations consume high quantities of soy food which is rich in isoflavones ( $2 \mathrm{~g}$ of isoflavones per $\mathrm{kg}$ of fresh soybean) (10). It has been shown that plasma and prostatic fluid concentrations of isoflavones in Asian men are 10 to 100 times higher than those in Western men, with particularly high levels of the isoflavone genistein $(11,12)$. An increasing body of population-based studies has demonstrated that high intake of soy isoflavones are associated with a 25-30\% reduced risk of prostate cancer $(13,14)$.

As the major biologically active isoflavone in the soy diet, genistein has been extensively investigated for its chemopreventive potential in various types of cancer, including prostate cancer. The average daily intake of genistein in Asian populations has been shown to be $20-80 \mathrm{mg}$ whereas it is $1-3 \mathrm{mg}$ in the USA, supporting the protective effects of genistein against prostate cancer in Asian men (15). Genistein reaches plasma concentrations of $1-5 \mu \mathrm{M}$ 6-8 h after intake of soyrich diet $(11,16)$. The plasma half-life of genistein has been reported as $7.9 \mathrm{~h}$ in adults. In addition, concentrations of total soy isoflavones in prostate tissue have been shown $\sim 6$-fold higher than serum levels of isoflavones (17). Safety and pharmacokinetic studies of soy isoflavones have demonstrated that minimal clinical toxicity was observed in healthy subjects administered with purified soy isoflavones at doses that exceed normal dietary intakes (18).

Due to its structural similarity to the steroid hormone $17 \beta$-estradiol, genistein binds to estrogen receptors, ER- $\alpha$ and ER- $\beta$, with a higher affinity to ER- $\beta$, and acts as a natural selective estrogen receptor modulator $(16,19,20)$. Genistein exerts its inhibitory effects on prostate cancer cells by upregulating the expression of ER- $\beta$, which has anti-proliferative and pro-apoptotic roles in prostate cells $(21,22)$. In addition to its estrogenic activities, genistein regulates androgen receptor (AR)-mediated pathways in prostate cancer $(23,24)$. Of note, it has been shown that the inhibitory effect of genistein on AR expression is also mediated by ER- $\beta$ (25). Several other molecular mechanisms underlying the preventive effects of genistein on prostate cancer include the inhibition of cell proliferation by inducing G1 and/or G2/M cell cycle arrest (26-28), angiogenesis $(29,30)$ and metastasis (31-33) and induction of apoptosis $(34,35)$. Genistein exerts its pleiotropic effects in the context of prostate cancer through modulation of several cell signal transduction pathways such as IGF-1 (36), TGF- $\beta$ (37), Wnt/ $\beta$-catenin (36), NF- $\mathrm{BB}$ (38), AKT and MAPK (39) signaling. This modulation could be by direct binding to nuclear receptors or modification of the phosphorylation state of signal transduction proteins. In addition, genistein inhibits tyrosine kinase activities (40) and shows antioxidant properties $(41,42)$ in prostate cells. Swami et al $(43)$ demonstrated that genistein reduces prostate cancer progression by inhibiting prostaglandin synthesis and activity. Genistein has also been reported to have possible effects on DNA damage and repair in prostate cancer cells (42). Moreover, genistein inhibits DNA methylation (44-48) and histone modifications $(47,48)$ and regulates miRNAs (49-52) in prostate cancer. It is of interest that genistein has been shown to enhance the efficacy of radiotherapy and chemotherapy $(53,54)$.
Although numerous in vitro and in vivo studies have been conducted to understand the protective effects of genistein against prostate cancer demonstrated by epidemiological studies, the molecular mechanisms that govern how genistein affects the pathogenesis of prostate cancer still remain elusive. It is noteworthy that a major challenge is the wide variability of the effects of genistein depending on the dose, the form of administration, or the timing and duration of exposure (55). Despite the wealth of studies performed in human cell lines and animal models, only a few prospective randomized clinical trials have been conducted to examine the molecular effects of genistein on prostate cancer. In the present study, to the best of our knowledge for the first time, we investigated the effects of genistein intervention on global methylation and gene expression patterns in patients with localized prostate cancer, and identified novel targets that are differentially modulated by genistein supplementation, providing further mechanistic insights into the effects of genistein on prostate carcinogenesis.

\section{Materials and methods}

Subjects. Prostate specimens from a clinical trial of genistein supplementation prior to prostatectomy (56) were analyzed for global changes in DNA methylation and gene expression. Participants were recruited from the outpatient clinic at the Department of Urology, Oslo University Hospital, Oslo, Norway between April 2007 and August 2008. The study was approved by the Norwegian Medicines Agency, the Regional Ethics Committee, the Privacy Ombudsman and the Prostate Biobank at the Oslo University Hospital, Aker.

Genome-wide methylation profiling. Total DNA was isolated from frozen prostate tissues using DNeasy Blood and Tissue kit (Qiagen, Valencia, CA, USA) according to the manufacturer's instructions. DNA was submitted to the Emory Integrated Genomics Core for DNA methylation analysis using Illumina HumanMethylation450 BeadChip Microarrays. Methylation data are available on GEO (accession number GSE84749).

Genome-wide expression profiling. Total RNA was extracted from frozen prostate tissues using the mirVana miRNA Isolation kit (Life Technologies, Grand Island, NY, USA), followed by RNA clean-up using the RNeasy Mini kit (Qiagen). Total RNA was submitted to the Emory Integrated Genomics Core for gene expression analysis using the Illumina HumanHT-12 v4 Expression BeadChip Microarray. Microarray data are available on GEO (accession number GSE84748).

Quantitative PCR ( $q P C R)$ analysis. RNA was reverse-transcribed into cDNA using iScript cDNA Synthesis kit (Bio-Rad Laboratories, Hercules, CA, USA). Primers were designed using Primer3 tool. Sequences of the primers are listed in Table I. qPCR was performed using iQ SYBR-Green Supermix (Bio-Rad Laboratories) on a Bio-Rad iCycler according to the manufacturer's protocols. Human $\beta$-actin gene, which has been shown to be a valid reference gene for normalization of qPCR in human tissue samples of prostate cancer, was used as an internal control in the present study (57). Normal prostate 
Table I. Sequences of the primers used in the quantitative PCR analysis.

\begin{tabular}{ll}
\hline Primer name & \multicolumn{1}{c}{ Primer sequence $\left(5^{\prime} \rightarrow 3^{\prime}\right)$} \\
\hline CKS2-FP & TTAGTCTCCGGCGAGTTGTTG \\
CKS2-RP & CATAACATGCCGGTACTCGT \\
JAG1-FP & AGTCGTGCATGCTCCAATCG \\
JAG1-RP & CCCCACACACCTTGGCTC \\
NOTCH3-FP & GATGTGGACGAGTGTGCTGG \\
NOTCH3-RP & CAGGCATGGGTTGGGGTC \\
MMP26-FP & GGACTTTGTTGAGGGCTATTCCA \\
MMP26-RP & GGAGGTGTCGGACCCATCAG \\
HIF1A-FP & CACCACAGGACAGTACAGGAT \\
HIF1A-RP & CGTGCTGAATAATACCACTCACA \\
CDK6-FP & GCTGACCAGCAGTACGAA TG \\
CDK6-RP & GCACACATCAAACAACCTGACC \\
CD24-FP & CGCGGACTTTTCTTTTGGGG \\
CD24-RP & ACTGGAATAAATCTGCGTGGGT \\
AMACR-FP & CCGTTCTGTGCTATGGTCCTG \\
AMACR-RP & AGCCTTGGATTTCCCGCTG \\
MYC-FP & CCTACCCTCTCAACGACAGC \\
MYC-RP & TTGTTCCTCCTCAGAGTCGC \\
SPP1-FP & CAAACGCCGACCAAGGAAAA \\
SPP1-RP & GGCCACAGCATCTGGGTATT \\
NEU1-FP & CGCAGCTATGATGCCTGTGA \\
NEU1-RP & GGTCAGGTTCACTCGGAACTC \\
ADCY4-FP & CCTGGGACCAGGTGTCCTAT \\
ADCY4-RP & CAAGATACAGCCCGAGGACC \\
$\beta$-actin-FP & CACAGAGCCTCGCCTTTGCC \\
$\beta$-actin-RP & TGACCCATGCCCACCATCAC \\
\hline
\end{tabular}

qPCR analysis.

tissue sample was used as the calibrator. The relative changes in gene expression data were analyzed by the $2^{-\Delta \Delta \mathrm{CT}}$ method. Triplicates were run for each sample. Data are presented as the mean \pm standard deviation.

Data analysis. Gene expression analysis was performed using GenePattern ComparativeMarkerSelection module (58) comparing genistein-treated tumors to placebo-treated tumors. Illumina Microarray data were filtered to include genes that were detected $(\mathrm{P}<0.05)$ in at least one experimental group to result in a dataset of 15918 genes for analysis. The comparative marker selection module of GenePattern was used to compute two-sided Student's t-tests between groups with 10,000 permutations to compute false discovery rates. The random seed used was 779948241 . Hierarchical clustering was performed using Cluster software (59) and Java TreeView (60). Methylation microarray analysis was performed in R using CpGassoc module in Bioconductor (61). Data from the $450 \mathrm{~K}$ probes was filtered to those in which the maximum - minimum $\beta$-value was $>0.2$ to result in $160 \mathrm{~K}$ probes for differential methylation analysis. CpGassoc was

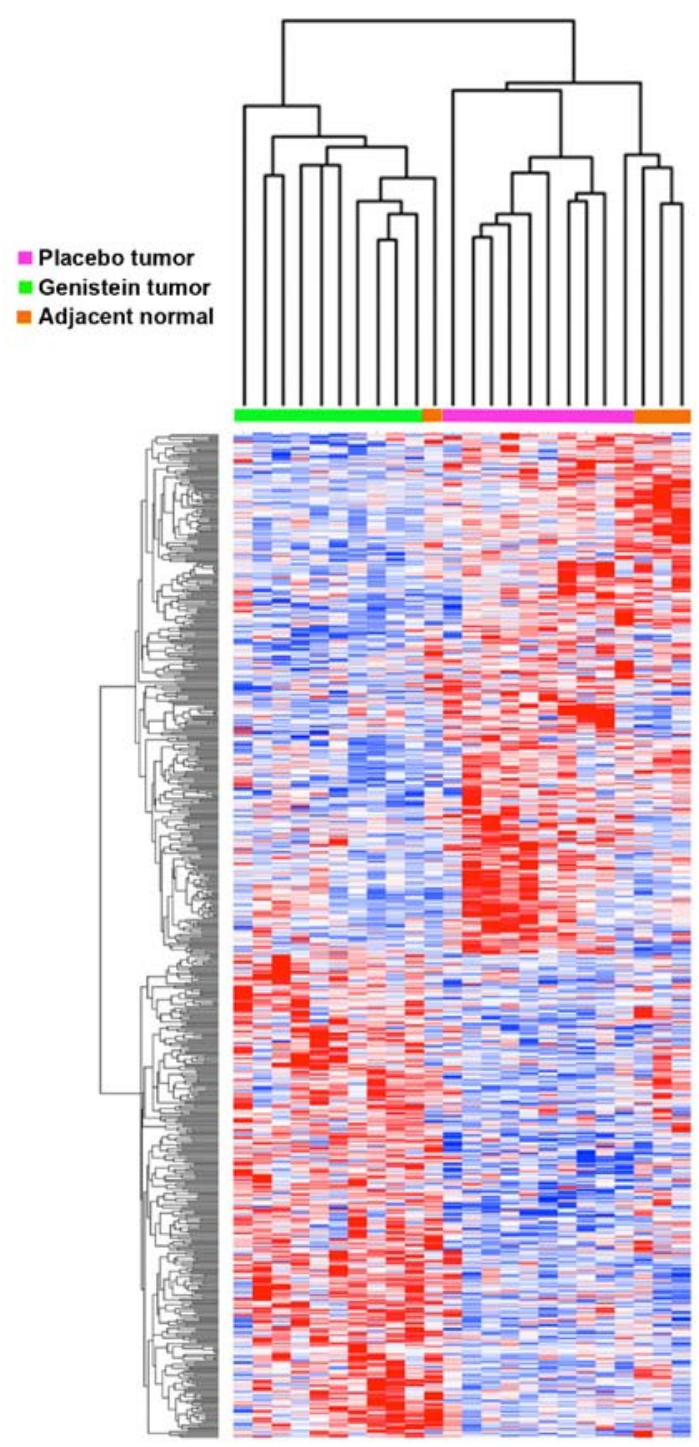

Figure 1. Whole genome expression profiling of placebo- or genistein-treated tumor samples. Hierarchical clustering of changes in gene expression for those genes with a nominal $\mathrm{P}<0.05$ between genistein-tumor samples and placebo-tumor samples.

used to identify 162 significant probes that were differentially methylated. Three probes were differentially methylated between genistein-treated tumor samples and placebo-treated tumor samples, three probes were significant between genistein-treated tumor samples and normal samples and 156 were significantly different between placebo-treated tumor samples and normal samples.

Statistical analysis. Mann-Whitney U test (two-tailed) was used to determine significant differences between two groups of data. $\mathrm{P}<0.05$ was considered as statistically significant.

\section{Results}

Clinicopathological characteristics. We analyzed prostate tissue samples from a previous study, which was a randomized, placebo-controlled, double-blind Phase 2 clinical trial on Norwegian patients with localized prostate cancer who received $30 \mathrm{mg}$ synthetic genistein or placebo capsules 
Table II. Clinical data for the 20 patients analyzed in the present study.

\begin{tabular}{|c|c|c|c|c|c|c|}
\hline Treatment & Patient ID & Gleason & Gleason Sum & Stage & Age & PSA \\
\hline \multirow[t]{10}{*}{ Genistein $(n=10)$} & 1 & $3+4$ & 7 & 2 & 68 & 12.0 \\
\hline & 7 & $3+4$ & 7 & 2 & 68 & 10.9 \\
\hline & 8 & $3+3$ & 6 & 2 & 59 & 6.2 \\
\hline & 10 & $3+4$ & 7 & $3 a$ & 61 & 5.1 \\
\hline & 13 & $3+3$ & 6 & 2 & 58 & 7.6 \\
\hline & 14 & $4+3$ & 7 & $3 a$ & 64 & 8.5 \\
\hline & 17 & $4+4$ & 8 & 2 & 61 & 6.1 \\
\hline & 18 & $3+3$ & 6 & 2 & 57 & 6.0 \\
\hline & 19 & $3+3$ & 6 & 2 & 63 & 7.8 \\
\hline & 20 & $3+4$ & 7 & 2 & 68 & 7.9 \\
\hline Average (SD) & & & $6.7(0.7)$ & & $62.7(4.2)$ & $7.8(2.2)$ \\
\hline \multirow[t]{10}{*}{ Placebo $(n=10)$} & 24 & $3+3$ & 6 & 2 & 61 & 6.4 \\
\hline & 25 & $3+3$ & 6 & 2 & 57 & 4.2 \\
\hline & 26 & $3+4$ & 7 & $3 a$ & 68 & 9.9 \\
\hline & 27 & $4+4$ & 8 & 2 & 69 & 9.2 \\
\hline & 30 & $4+3$ & 7 & 2 & 55 & 5.1 \\
\hline & 33 & $3+3$ & 6 & 2 & 56 & 6.4 \\
\hline & 34 & $3+3$ & 6 & 2 & 63 & 7.6 \\
\hline & 35 & $3+4$ & 7 & $3 a$ & 60 & 5.7 \\
\hline & 38 & $3+4$ & 7 & 2 & 62 & 9.9 \\
\hline & 39 & $3+3$ & 6 & 2 & 66 & 7.0 \\
\hline Average (SD) & & & $6.6(0.7)$ & & $61.7(4.9)$ & $7.1(2.0)$ \\
\hline
\end{tabular}

daily for 3-6 weeks before radical prostatectomy (56). The clinical and pathological characteristics of the cases were previously described (56). The availability of frozen tissue limited the sample size in this study and we investigated the DNA methylation and gene expression levels of prostate tumor samples from 10 patients who received genistein and 10 patients who received placebo. Four adjacent normal prostate tissue samples were also analyzed. Clinical data for the 20 patients analyzed here are provided in Table II. There were no statistically significant differences in age, levels of serum PSA and Gleason score between the two treatment groups.

Differential methylation in genistein-treated tissue compared with placebo-treated tissue.The genome-wideDNA methylation profiles of a total of 24 prostate samples from tumor or normal tissues were generated using Illumina HumanMethylation450 BeadChip kit. Methylation status of each sample was analyzed for 485,577 sites, covering 21,231 genes. We compared the methylation profiles of genistein-treated tumor samples with placebo-treated cases. In general, methylation changes were modest, and there was no significantly differentially methylated gene after correction for multiple hypothesis testing. However, uncorrected P-values indicated that $R B M 28$ and $C Y T S B$ genes were demethylated in genistein-treated tumor samples compared to placebo-treated samples. The lack of statistical significance was likely due to the small numbers of samples analyzed in this study. We did observe 156 probes with significantly increased methylation in placebo-treated tumor tissues vs. normal tissues that were not significant between genistein-treated tumor tissues and normal tissues, suggesting that genistein may have had some demethylation effects (available upon request). These 156 probes corresponded to at least 92 separate genes including ADCY4, ALOX12, HAAO, LRRC4, NEU1, RAPGEFL1 and WNT7B (Table III).

Gene expression profiling changes after genistein treatment. To identify molecular effects of genistein on mRNA levels in prostate cancer, we compared gene expression profiles of genistein-treated tumors with placebo-treated samples. Once again, there were no differentially expressed probes that remained statistically significant after correction for multiple hypothesis testing. However, there were 628 probes that reached nominally significant P-values (available upon request). Hierarchial clustering of this dataset showed strong segregation of patients with and without genistein treatment (Fig. 1). The genes with nominally significant P-values included NOTCH3, JAG1, $C K S 2, H I F 1 A, C D K 6, M Y C, C D 24, A M A C R, M M P 26$ and SPPl genes (Table IV). NEU1 and ADCY4 did not reach nominal significance but had a trend towards significance, and integration of the methylation data with the paired gene expression profiling data indicated decreased methylation status and increased expression levels of ADCY4 and NEU1 genes in genistein-treated cases.

Validation of microarray data. We investigated the expression levels of 12 selected genes (Table IV) in all 24 samples analyzed 
Table III. List of 156 differentially methylated probes (92 genes).

\begin{tabular}{|c|c|c|c|c|}
\hline Target ID & Gene name & P-value (GT vs. PT) & P-value (GT vs. N) & P-value (PT vs. N) \\
\hline $\operatorname{cg} 00353923$ & LRRC4; SND1 & ns & ns & 0.000214451 \\
\hline $\operatorname{cg} 00420348$ & EFCAB4A & ns & ns & 0.000247793 \\
\hline $\operatorname{cg} 00459232$ & CD9 & ns & ns & 0.000270319 \\
\hline $\operatorname{cg} 00494665$ & & ns & ns & 0.000274219 \\
\hline $\operatorname{cg} 00506168$ & PDXK & ns & ns & 0.000515556 \\
\hline $\operatorname{cg} 00578638$ & RAPGEFL1 & ns & ns & $3.67 \mathrm{E}-05$ \\
\hline $\operatorname{cg} 01224366$ & PDXK & ns & ns & 0.000393857 \\
\hline $\operatorname{cg} 01228355$ & CORIN & ns & ns & 0.000881032 \\
\hline $\operatorname{cg} 01233722$ & NFATC4 & ns & ns & $1.51 \mathrm{E}-05$ \\
\hline $\operatorname{cg} 01398859$ & & ns & ns & 0.000942104 \\
\hline $\operatorname{cg} 01561916$ & HAAO & ns & ns & 0.00015216 \\
\hline $\operatorname{cg} 01684881$ & FZD2 & ns & ns & 0.000472597 \\
\hline $\operatorname{cg} 01856645$ & DMGDH; BHMT2 & ns & ns & 0.000876054 \\
\hline $\operatorname{cg} 02072400$ & & ns & ns & $3.73 \mathrm{E}-05$ \\
\hline cg02131967 & $\mathrm{ACE}$ & ns & ns & 0.000468338 \\
\hline $\operatorname{cg} 02215070$ & AKR1B1 & ns & ns & 0.000607743 \\
\hline $\operatorname{cg} 02493798$ & ALOX12 & ns & ns & 0.000106934 \\
\hline $\operatorname{cg} 02534363$ & NBEAL2 & ns & ns & 0.000263128 \\
\hline cg02659920 & EPS8L2 & ns & ns & 0.000563556 \\
\hline $\operatorname{cg} 02665650$ & ANKS1A & ns & ns & 0.000420543 \\
\hline cg02683114 & C2orf84 & $\mathrm{ns}$ & $\mathrm{ns}$ & $3.28 \mathrm{E}-05$ \\
\hline $\operatorname{cg} 02915422$ & & $\mathrm{~ns}$ & ns & 0.000993538 \\
\hline cg03119308 & RBM28 & 0.000122845 & ns & ns \\
\hline $\operatorname{cg} 03404566$ & ALOX12 & ns & ns & $9.44 \mathrm{E}-05$ \\
\hline $\operatorname{cg} 03407747$ & ALOX12 & ns & ns & 0.000320776 \\
\hline $\operatorname{cg} 03452174$ & RAB34 & $\mathrm{ns}$ & $\mathrm{ns}$ & 0.000820466 \\
\hline $\operatorname{cg} 03456213$ & C9orf3 & $\mathrm{ns}$ & ns & 0.000620827 \\
\hline $\operatorname{cg} 03760483$ & ALOX12 & $\mathrm{ns}$ & ns & 0.000249903 \\
\hline cg03762994 & ALOX12 & ns & ns & 0.000338148 \\
\hline $\operatorname{cg} 03782157$ & & $\mathrm{~ns}$ & $\mathrm{~ns}$ & 0.000566959 \\
\hline $\operatorname{cg} 03787864$ & CYBA & $\mathrm{ns}$ & ns & 0.000360395 \\
\hline $\operatorname{cg} 03955537$ & TBCD & $\mathrm{ns}$ & $\mathrm{ns}$ & 0.000449056 \\
\hline cg03957885 & & ns & ns & 0.000500821 \\
\hline $\operatorname{cg} 04034767$ & GRASP & ns & ns & 0.000526517 \\
\hline $\operatorname{cg} 04178858$ & RAPGEFL1 & ns & ns & 0.000378136 \\
\hline $\operatorname{cg} 04194674$ & SRCIN1 & $\mathrm{ns}$ & ns & 0.000665658 \\
\hline $\operatorname{cg} 04332818$ & FGF2 & $\mathrm{ns}$ & ns & 0.000648814 \\
\hline $\operatorname{cg} 04555220$ & SEMA5A & ns & ns & 0.000994353 \\
\hline $\operatorname{cg} 04621728$ & & ns & ns & 0.000680098 \\
\hline $\operatorname{cg} 04797170$ & & ns & ns & 0.000729496 \\
\hline cg05209996 & & ns & ns & 0.000724896 \\
\hline $\operatorname{cg} 05897210$ & DTHD1 & ns & ns & 0.000252462 \\
\hline $\operatorname{cg} 05950572$ & SPON1 & ns & ns & 0.000546993 \\
\hline $\operatorname{cg} 06085985$ & EFCAB4A & ns & ns & 0.000230613 \\
\hline $\operatorname{cg} 06590173$ & TPM4 & $\mathrm{ns}$ & ns & 0.000778707 \\
\hline cg06607764 & CYTH1 & ns & ns & 0.000254746 \\
\hline $\operatorname{cg} 06749789$ & THAP4 & $\mathrm{ns}$ & ns & 0.000864909 \\
\hline $\operatorname{cg} 06763054$ & MTMR7 & ns & ns & 0.000353509 \\
\hline $\operatorname{cg} 06795971$ & TET2 & ns & ns & 0.000140266 \\
\hline $\operatorname{cg} 06835156$ & C14orf70 & ns & 0.000524942 & ns \\
\hline $\operatorname{cg} 06945399$ & LRRC4; SND1 & ns & ns & 7.67E-05 \\
\hline $\operatorname{cg} 07016556$ & BAHCC1 & ns & ns & 0.000590044 \\
\hline $\operatorname{cg} 07235805$ & PARD6G & ns & ns & 0.000661791 \\
\hline $\operatorname{cg} 07251099$ & CD200 & ns & ns & 0.000689192 \\
\hline
\end{tabular}


Table III. Continued.

\begin{tabular}{|c|c|c|c|c|}
\hline Target ID & Gene name & P-value (GT vs. PT) & P-value (GT vs. N) & P-value (PT vs. N) \\
\hline $\operatorname{cg} 07522516$ & ZAR1 & ns & ns & 0.000692555 \\
\hline $\operatorname{cg} 07834955$ & SFRP5 & ns & ns & 0.000372927 \\
\hline $\operatorname{cg} 07871590$ & LRRC4;SND1 & $\mathrm{ns}$ & ns & 0.000127567 \\
\hline $\operatorname{cg} 07924363$ & MGC16121; MIR424; MIR503 & ns & 0.000320255 & ns \\
\hline $\operatorname{cg} 08194377$ & ANKS1A & ns & ns & 0.000793165 \\
\hline $\operatorname{cg} 08248285$ & CFL2 & ns & ns & 0.000346449 \\
\hline $\operatorname{cg} 08298946$ & & ns & ns & 0.000455024 \\
\hline $\operatorname{cg} 08330950$ & & $\mathrm{~ns}$ & ns & 0.000195062 \\
\hline $\operatorname{cg} 08421126$ & HAAO & ns & ns & 0.000388422 \\
\hline $\operatorname{cg} 08572315$ & & ns & ns & 0.000667361 \\
\hline $\operatorname{cg} 08617833$ & SMARCA1 & $\mathrm{ns}$ & ns & 0.000373883 \\
\hline $\operatorname{cg} 09088834$ & NINL & ns & ns & 0.000442225 \\
\hline $\operatorname{cg} 09246479$ & C22orf45; UPB1 & ns & ns & 0.00010158 \\
\hline $\operatorname{cg} 09456782$ & TMCO3; DCUN1D2 & ns & ns & 0.000792785 \\
\hline $\operatorname{cg} 09480054$ & HAAO & ns & ns & 0.000295903 \\
\hline $\operatorname{cg} 09580336$ & ATP1A1 & ns & ns & 0.000440859 \\
\hline $\operatorname{cg} 09581551$ & SOBP & ns & ns & 0.000280079 \\
\hline cg09667289 & FMN1 & ns & ns & 0.000712725 \\
\hline cg09737314 & ALOX12 & ns & ns & 0.000673337 \\
\hline cg09920557 & $\mathrm{ACE}$ & ns & ns & 0.000673976 \\
\hline cg09963123 & FLJ13197; KLF3 & ns & ns & 0.000654359 \\
\hline $\operatorname{cg} 10445911$ & & ns & ns & 0.00061326 \\
\hline $\operatorname{cg} 11417025$ & SOSTDC1 & $\mathrm{ns}$ & ns & 0.000375888 \\
\hline $\operatorname{cg} 11832404$ & & ns & ns & 0.000826709 \\
\hline $\operatorname{cg} 11942956$ & EYA4 & $\mathrm{ns}$ & ns & 0.00073108 \\
\hline $\operatorname{cg} 12177793$ & NFATC4 & ns & ns & 0.000965995 \\
\hline $\operatorname{cg} 12262378$ & ALOX12 & ns & ns & 0.000115607 \\
\hline $\operatorname{cg} 12451530$ & LOC100302652; GPR75 & ns & ns & 0.000188564 \\
\hline $\operatorname{cg} 12828075$ & INSC & ns & ns & 0.000784835 \\
\hline $\operatorname{cg} 13616314$ & HS3ST3A1 & ns & ns & 2.38E-05 \\
\hline $\operatorname{cg} 13801416$ & AKR1B1 & $\mathrm{ns}$ & ns & 0.000474669 \\
\hline $\operatorname{cg} 13857811$ & SLC7A3 & ns & ns & 0.000228168 \\
\hline $\operatorname{cg} 14032732$ & ECHDC3 & ns & ns & 0.000256212 \\
\hline $\operatorname{cg} 14243778$ & CNTN1 & ns & ns & 0.00077315 \\
\hline $\operatorname{cg} 14254720$ & LRRC8C & ns & ns & 0.000920384 \\
\hline $\operatorname{cg} 14287235$ & ADCY4 & ns & ns & 0.000228476 \\
\hline $\operatorname{cg} 14482902$ & SRCIN1 & $\mathrm{ns}$ & ns & 0.000344968 \\
\hline $\operatorname{cg} 14500300$ & & ns & ns & $8.80 \mathrm{E}-05$ \\
\hline $\operatorname{cg} 14603620$ & RAPGEFL1 & ns & ns & 7.94E-05 \\
\hline $\operatorname{cg} 14663984$ & AGRN & ns & ns & 0.000843468 \\
\hline $\operatorname{cg} 14792081$ & & ns & ns & 0.000344126 \\
\hline $\operatorname{cg} 15115171$ & & $\mathrm{~ns}$ & ns & 0.000503109 \\
\hline $\operatorname{cg} 15673034$ & DLGAP1 & $\mathrm{ns}$ & ns & 0.000846318 \\
\hline $\operatorname{cg} 15826437$ & RAPGEFL1 & $\mathrm{ns}$ & ns & 0.00029995 \\
\hline $\operatorname{cg} 15998779$ & & ns & ns & 0.000211956 \\
\hline $\operatorname{cg} 16450577$ & TBCD & $\mathrm{ns}$ & ns & 0.000368573 \\
\hline $\operatorname{cg} 16859884$ & & ns & ns & 0.000247308 \\
\hline $\operatorname{cg} 16968985$ & SEZ6 & ns & ns & 0.000382576 \\
\hline $\operatorname{cg} 17011709$ & CYP26C1 & ns & ns & 0.000901702 \\
\hline $\operatorname{cg} 17131553$ & TRPS1 & $\mathrm{ns}$ & ns & 0.000583708 \\
\hline $\operatorname{cg} 17165580$ & CRABP2 & ns & ns & 0.000197886 \\
\hline $\operatorname{cg} 17479501$ & TBCD & ns & ns & 0.000197189 \\
\hline $\operatorname{cg} 17496661$ & & ns & 0.000436474 & 0.000459741 \\
\hline $\operatorname{cg} 17624073$ & BAHCC1 & $\mathrm{ns}$ & ns & 0.000526316 \\
\hline
\end{tabular}


Table III. Continued.

\begin{tabular}{|c|c|c|c|c|}
\hline Target ID & Gene name & P-value (GT vs. PT) & P-value (GT vs. N) & P-value (PT vs. N) \\
\hline $\operatorname{cg} 17729667$ & NINL & ns & ns & 0.000569462 \\
\hline $\operatorname{cg} 18344652$ & CNN3 & ns & ns & 0.000452391 \\
\hline $\operatorname{cg} 19372602$ & & ns & ns & 0.000864447 \\
\hline $\operatorname{cg} 19467964$ & TBCD & ns & ns & 0.000196505 \\
\hline $\operatorname{cg} 19499884$ & LZTS2 & ns & $\mathrm{ns}$ & 0.000537829 \\
\hline $\operatorname{cg} 19929126$ & TRIL & ns & ns & 0.000632594 \\
\hline $\operatorname{cg} 20132775$ & TRPC1 & ns & ns & 0.000197515 \\
\hline $\operatorname{cg} 20145692$ & COL9A2 & ns & $\mathrm{ns}$ & 0.000190537 \\
\hline $\operatorname{cg} 20276377$ & C3orf26; FILIP1L; MIR548G & ns & ns & $6.22 \mathrm{E}-05$ \\
\hline $\operatorname{cg} 20383155$ & NEU1; SLC44A4 & ns & $\mathrm{ns}$ & 0.000632549 \\
\hline $\operatorname{cg} 20801007$ & EFCAB4A & ns & ns & 0.000259905 \\
\hline cg20987431 & ZHX1 & ns & ns & 0.00053928 \\
\hline $\operatorname{cg} 21079003$ & RGMA & ns & ns & 0.000411886 \\
\hline $\operatorname{cg} 21116447$ & NEU1; SLC44A4 & ns & $\mathrm{ns}$ & 0.000990119 \\
\hline $\operatorname{cg} 21543859$ & RUNX2 & ns & ns & 0.000760409 \\
\hline $\operatorname{cg} 21849932$ & LIME1 & ns & ns & 0.000537283 \\
\hline $\operatorname{cg} 21944491$ & LTBP4 & ns & ns & 0.000572287 \\
\hline $\operatorname{cg} 22074576$ & OSBPL5 & $\mathrm{ns}$ & ns & 0.00073274 \\
\hline $\operatorname{cg} 22092811$ & C3orf26; FILIP1L; MIR548G & ns & $\mathrm{ns}$ & 4.30E-05 \\
\hline $\operatorname{cg} 22413388$ & WNT7B & ns & ns & 0.000992683 \\
\hline $\operatorname{cg} 22534145$ & SSTR4 & ns & ns & 0.000156886 \\
\hline $\operatorname{cg} 22675801$ & TRIL & ns & ns & 0.000451146 \\
\hline $\operatorname{cg} 22753340$ & NEU1; SLC44A4 & ns & $\mathrm{ns}$ & 0.000874186 \\
\hline $\operatorname{cg} 22773555$ & EFCAB4A & ns & $\mathrm{ns}$ & 0.00025263 \\
\hline cg22773661 & ZAR1 & ns & ns & 0.00033279 \\
\hline $\operatorname{cg} 22871668$ & EYA4 & $\mathrm{ns}$ & ns & 0.000392704 \\
\hline $\operatorname{cg} 22878441$ & & $\mathrm{~ns}$ & ns & 0.000393322 \\
\hline $\operatorname{cg} 23083315$ & FJX1 & $\mathrm{ns}$ & $\mathrm{ns}$ & 0.000288759 \\
\hline $\operatorname{cg} 23142799$ & SHISA2 & $\mathrm{ns}$ & $\mathrm{ns}$ & 0.000157373 \\
\hline $\operatorname{cg} 23396786$ & SFXN5 & $\mathrm{ns}$ & $\mathrm{ns}$ & 0.000434986 \\
\hline $\operatorname{cg} 23425970$ & HS6ST1 & $\mathrm{ns}$ & ns & 0.00016049 \\
\hline $\operatorname{cg} 23563927$ & C10orf93 & $\mathrm{ns}$ & $\mathrm{ns}$ & 0.000585909 \\
\hline $\operatorname{cg} 23684878$ & & $\mathrm{~ns}$ & $\mathrm{~ns}$ & 0.000735566 \\
\hline $\operatorname{cg} 23926436$ & & $\mathrm{~ns}$ & $\mathrm{~ns}$ & 0.00082097 \\
\hline $\operatorname{cg} 24251193$ & CRABP2 & $\mathrm{ns}$ & $\mathrm{ns}$ & 0.000141885 \\
\hline $\operatorname{cg} 24331301$ & $\mathrm{CDH} 23$ & $\mathrm{~ns}$ & $\mathrm{~ns}$ & 0.000549748 \\
\hline $\operatorname{cg} 24878115$ & SSBP4 & $\mathrm{ns}$ & $\mathrm{ns}$ & 0.000354342 \\
\hline $\operatorname{cg} 24902339$ & CASC2 & ns & ns & 0.000256574 \\
\hline $\operatorname{cg} 25027125$ & CFL2 & ns & ns & 0.000978881 \\
\hline $\operatorname{cg} 25117523$ & CYTH1 & ns & ns & 0.000297582 \\
\hline $\operatorname{cg} 25387565$ & NEU1 & ns & ns & 0.000708206 \\
\hline $\operatorname{cg} 25563256$ & FGF11 & $\mathrm{ns}$ & $\mathrm{ns}$ & 0.000933724 \\
\hline $\operatorname{cg} 25813864$ & RAPGEFL1 & ns & ns & 0.000174816 \\
\hline $\operatorname{cg} 25834415$ & KIF1A & $\mathrm{ns}$ & ns & 0.000894051 \\
\hline $\operatorname{cg} 26009486$ & NFATC4 & $\mathrm{ns}$ & $\mathrm{ns}$ & 0.000293111 \\
\hline $\operatorname{cg} 26360792$ & HAAO & $\mathrm{ns}$ & ns & 0.000297095 \\
\hline $\operatorname{cg} 26558799$ & TBCD & $\mathrm{ns}$ & $\mathrm{ns}$ & 0.000570916 \\
\hline cg26607748 & TPM2 & ns & ns & 0.000773141 \\
\hline $\operatorname{cg} 26846076$ & CYTSB & 0.000457469 & ns & ns \\
\hline $\operatorname{cg} 27191312$ & & ns & ns & 0.00012339 \\
\hline $\operatorname{cg} 27299406$ & HAAO & $\mathrm{ns}$ & $\mathrm{ns}$ & 0.000380895 \\
\hline $\operatorname{cg} 27347290$ & NEU1; SLC44A4 & $\mathrm{ns}$ & ns & 0.000429935 \\
\hline $\operatorname{cg} 27573591$ & SND1; LRRC4 & $\mathrm{ns}$ & ns & 0.000183694 \\
\hline rs 10033147 & & 0.00000393 & ns & ns \\
\hline
\end{tabular}

GT, genistein-treated tumor; PT, placebo-treated tumor; N, normal; NS, not significant. 

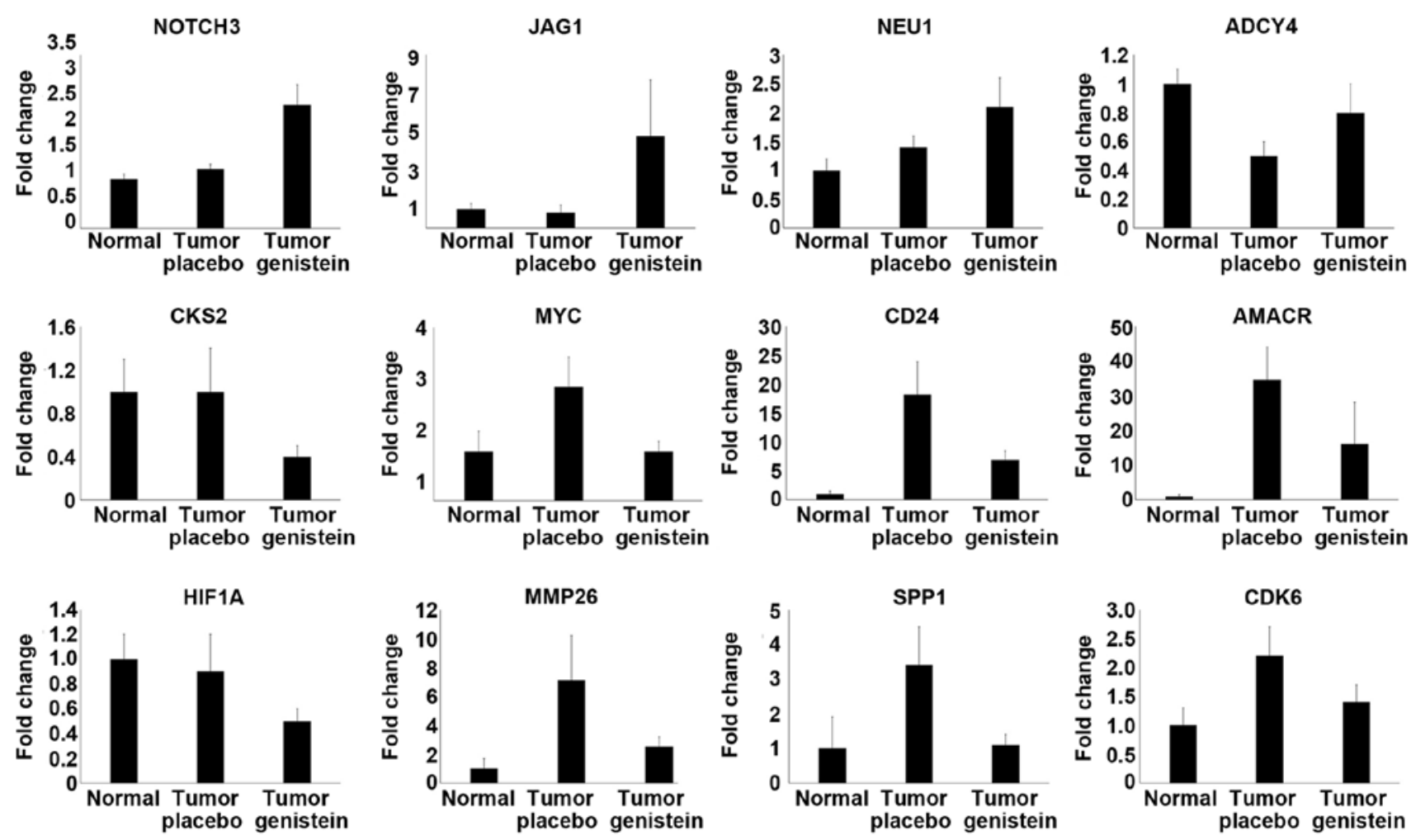

Figure 2. qPCR analysis of expression levels of 12 genes in placebo and genistein groups. Expression changes of the genes selected from the microarray data were validated using qPCR. The data are presented as fold-changes relative to the control samples. qPCR, quantitative PCR.

Table IV. Genes with differential gene expression analyzed by qPCR.

\begin{tabular}{lcc}
\hline & \multicolumn{2}{c}{$\begin{array}{c}\text { Gene expression } \\
\text { fold-change }\end{array}$} \\
\cline { 2 - 3 } Gene symbol & Microarray & qPCR \\
\hline$C K S 2$ & -2.02 & -2.50 \\
NOTCH3 & 1.72 & 2.08 \\
HIF1A & -1.63 & -1.80 \\
$C D K 6$ & -2.87 & -1.57 \\
$J A G 1$ & 1.91 & 6.00 \\
NEU1 & 1.77 & 1.50 \\
aDCY4 & 1.67 & 1.60 \\
MYC & -1.57 & -2.30 \\
$C D 24$ & -2.02 & -2.64 \\
AMACR & -1.95 & -2.14 \\
MMPP26 & -2.78 & -2.84 \\
SPP1 & -2.36 & -3.09 \\
\hline
\end{tabular}

Fold changes are genistein-tumor/placebo-tumor. ${ }^{a} \mathrm{DNA}$ methylation status is correlated with gene expression in NEU1 and ADCY4.qPCR, quantitative PCR.

by microarrays using qPCR, and observed that microarray data were correlated with qPCR results (Fig. 2). The increase in the qPCR expression levels of NOTCH3 and JAG1 genes in genistein-treated tumors compared to placebo-treated tumors were statistically significant by Mann-Whitney U test.

Enrichment analysis. We performed gene enrichment analysis on the 628 nominally significant probes that were differentially expressed between genistein and placebo samples (Table V) using Ingenuity Pathway Analysis (62) and the DAVID Knowledgebase (63). P-value indicates hypergeometric distribution P-values of overlap for gene sets and functional categories. FDR indicates false discovery rate corrected P-values of overlap. Activation z-score is an indication of the consistency of up and downregulated members of a gene set such as a biological function (top table) or targets of an upstream regulator (middle table). Activation z-scores $>2$ or $<-2$ are statistically significant for consistency of activation or inhibition. Molecules indicate the number of molecules in the set of 628 analyzed probes that overlap with a given category. Mechanistic network indicates the total number of target genes of an upstream regulator, and the number of overlapping genes is indicated in parentheses. We observed enrichment for terms associated with angiogenesis, apoptosis, epithelial to mesenchymal transition, tumor progression and PDGF binding. Analysis of potential upstream regulators by IPA analysis suggested that PTEN and PDGF were activated, while MYC, $\beta$-estradiol, glucocorticoid receptor NR3C1 and interferon- $\gamma$ were repressed in response to genistein treatment.

\section{Discussion}

To the best of our knowledge, the present study is the first highlighting the effects of genistein on global changes in DNA 
Table V. Enrichment analysis of 628 nominally significant probes differentially expressed between genistein and placebo groups.

\begin{tabular}{|c|c|c|c|c|}
\hline Analysis & P-value & Activation z-score & No. of molecules & Function \\
\hline IPA & $5.92 \mathrm{E}-08$ & 0.773 & 18 & Progression of tumor \\
\hline IPA & 4.88E-07 & 1.01 & 355 & Abdominal neoplasm \\
\hline IPA & $1.09 \mathrm{E}-06$ & 1.927 & 28 & Differentiation of tumor cell lines \\
\hline IPA & $1.34 \mathrm{E}-06$ & -1.017 & 19 & Epithelial-mesenchymal transition \\
\hline IPA & $7.46 \mathrm{E}-06$ & 2.412 & 22 & Neuroendocrine tumor \\
\hline IPA & 7.98E-05 & 2.054 & 28 & Necrosis of tumor \\
\hline Analysis & P-value of overlap & Activation z-score & Mechanistic network & Upstream regulator \\
\hline IPA & $3.85 \mathrm{E}-08$ & -0.692 & $184(16)$ & NR3C1 \\
\hline IPA & $1.21 \mathrm{E}-07$ & 1.681 & $112(9)$ & PDGFB \\
\hline IPA & $2.71 \mathrm{E}-07$ & -1.385 & $167(15)$ & $\beta$-estradiol \\
\hline IPA & $2.15 \mathrm{E}-06$ & -0.832 & $144(13)$ & IFNG \\
\hline IPA & 2.17E-06 & 1.608 & $141(16)$ & PTEN \\
\hline IPA & 4.59E-06 & -2.995 & $133(13)$ & MYC \\
\hline Analysis & FDR & Activation z-score & No. of molecules & Term \\
\hline DAVID & $7.90 \mathrm{E}-04$ & NA & 17 & GO:0005840 ribosome \\
\hline DAVID & 1.19E-02 & NA & 34 & mitochondrion \\
\hline DAVID & $2.00 \mathrm{E}-02$ & NA & 16 & $\begin{array}{l}\text { GO:0001568 blood vessel } \\
\text { development }\end{array}$ \\
\hline DAVID & $1.77 \mathrm{E}-02$ & NA & 10 & GO:0019838 growth factor binding \\
\hline DAVID & $3.52 \mathrm{E}-02$ & NA & 7 & $\begin{array}{l}\text { GO:0008629 induction of apoptosis } \\
\text { by intracellular signals }\end{array}$ \\
\hline DAVID & $3.16 \mathrm{E}-02$ & NA & 4 & $\begin{array}{l}\text { GO:0048407 platelet-derived } \\
\text { growth factor binding }\end{array}$ \\
\hline
\end{tabular}

methylation and gene expression in patients from a clinical trial of genistein in prostate cancer. Integrative analysis of whole genome methylation and expression profiling identified a number of candidate differentially methylated sites and expressed sites between placebo and genistein groups. However, the differences between placebo and genistein groups were not statistically significant after correction for multiple hypothesis testing, possibly due to the small number of the cases in this study. Although the genistein-induced alterations are not significant, these results may help to elucidate the molecular mechanisms underlying the activities of genistein in prostate cancer. Genome-wide DNA methylation arrays showed that a number of genes, including $R B M 28$ and $C Y T S B$, appeared to be demethylated in the genistein-treated tumor samples compared to the samples in the placebo group. However, we did not observe any alterations in the expression levels of these genes. Among the differentially expressed genes identified by microarray analysis were $C K S 2, N O T C H 3$, HIF1A, CDK6, JAG1, NEU1, ADCY4, MYC, CD24, AMACR, $M M P 26$ and SPP1. Microarray data were confirmed by qPCR analysis of these genes. Other genes with nominal significance by microarray but not tested by qPCR included ZNF639, CRIM1, PGC and USP54 (available upon request).

It is of interest to note that DNA methylation status was inversely correlated with gene expression for the NEUI and
$A D C Y 4$ genes, which had decreased methylation, and increased mRNA expression in the genistein group in comparison with placebo group. Our finding showing the potential of genistein for DNA demethylation is consistent with the previously reported data that suggest genistein acts as a DNMT inhibitor, thereby causing the demethylation of $\mathrm{CpG}$ islands in the promoters of genes. For example, genistein has been shown to reactivate the hypermethylated-silenced tumor suppressor genes, including pl6INK $4 a$, retinoic acid receptor $\beta(R A R \beta)$ and 06 -methylguanine methyltransferase (MGMT), in prostate and esophageal cancer cells (46). Moreover, genistein has been implicated in demethylation of WNT5 a promoter in colon cancer cells (64). One of the genes shown to be demethylated by genistein in the present study is ADCY4, which is a member of the family of adenylate cyclases, the membrane-bound enzymes that catalyze formation of the secondary messenger cyclic adenosine monophosphate (cAMP) (65). Consistent with our finding, it has been recently shown that ADCY4 is a DNA methylation marker representing early epigenetic events in prostate tumorigenesis, supporting our hypothesis that genistein may reverse the pattern of DNA methylation in ADCY4 in prostate cancer (66). The other gene that was modulated by genistein intervention in the present study was NEU1, which is a lysosomal sialidase involved in glycoconjugate catabolism and cellular signaling, including immune responses and elastin 
receptor-mediated signal transduction (67). In fact, NEU1 is critical for desialylation of integrin $\beta 4$ and inhibition of FAK, leading to suppression of liver metastases in colon cancer (68). Kato et al (69) has reported that NEU1 overexpression resulted in suppression of lung metastasis in melanoma. In addition, suppression of NEU1 by miR-125b has been shown to promote migration, invasion and metastasis in gastric cancers (70). However, NEU1 can also have pro-metastatic effects in pancreatic and ovarian cancers (71), and thus it is not entirely clear what the overall impact of increased NEU1 levels might be in prostate cancer. Therefore, it is important to examine the NEU1 expression changes at the protein level, and molecular and cellular studies are required to assess the functional consequences of changes induced by NEU1 upregulation in prostate cancer cells.

Among the differentially expressed genes that were validated by qPCR, only the expression of NOTCH3 and $J A G 1$ mRNAs were significantly higher in the genistein group compared to the placebo group by qPCR. Based on our findings at mRNA level without any confirmation at the protein or functional level, it would be speculative to suggest that Notch signaling may play a role in the mechanism of action of genistein on prostate cancer. NOTCH3 is important for TGF $\beta$-induced EMT in prostate cancer (72), and is induced by hypoxia and contributes to prostate cancer progression (73). The Notch ligand JAG1 is also associated with more aggressive prostate cancer $(74,75)$, EMT and angiogenesis (76). However, a tumor suppressive role of Notch signaling has also been reported in hypoxia-induced neuroendocrine differentiation of prostate cancer cells as well as in other cancer types including bladder cancer, hematological malignancies, glioma, thyroid carcinoma and lung cancer (77-82), indicating the possibility that increased NOTCH3/JAG1 expression by genistein treatment may improve outcomes through its tumor suppressor function. Our data suggest that further studies to delineate the effect of genistein on the Notch signaling pathway in prostate cancer may be warranted.

Enrichment analyses of mRNA changes induced by genistein indicated that subtle changes in gene expression observed between genistein and placebo samples are consistent with many previously reported effects of genistein on critical tumor pathways including PTEN, PDGF, MYC, $\beta$-estradiol, glucocorticoid receptor and interferon- $\gamma$ (41,83-89). Genistein appeared to promote PTEN activity and inhibit MYC activity, consistent with its potential utility in improving outcomes in prostate cancer.

In summary, our results indicate that genistein intervention induces modulation of several genes, including NOTCH3, $J A G 1, A D C Y 4$ and NEU1, suggesting that these genes may have the potential to be novel molecular targets of genistein in prostate cancer. These genes are involved in many critical biological processes including cell cycle, angiogenesis, cellular immune response and intracellular signal transduction, providing additional insight into the multiple molecular pathways involved in prostate tumorigenesis. However, further mechanistic studies are required to investigate the effects of genistein on the regulation of the expression of these genes at the protein level and cellular functions. These findings may then contribute towards designing novel strategies for prevention and treatment of prostate cancer. One caveat of gene expression profiling studies is the incapability of identification of mechanisms of action that are modulated at post-transcriptional level, suggesting the possibility that genistein may alter additional cellular processes. Another point that needs to be made is timing and duration of exposure to genistein. Case control studies have demonstrated that high consumption of soy early in life (during childhood and/or adolescence) is associated with $25-60 \%$ reductions in breast cancer risk $(90,91)$. Similarly, high soy intake at puberty, the period during which prostate undergoes androgen-induced growth, might be more effective in prevention of prostate cancer. A limitation of the present study is the small number of patient samples. Further large randomized controlled clinical trials would provide more definitive results of the effects of genistein on patient prostate tissues.

\section{Acknowledgements}

The present study was supported in part by the Emory Integrated Genomics Core (EIGC), which is subsidized by the NCI Cancer Center Support Grant P30CA138292 and Emory University School of Medicine and is one of the Emory Integrated Core Facilities. It was further supported by a Soy Research Award from the Soy Health Research Program of the United Soybean Board.

\section{References}

1. Siegel RL, Miller KD and Jemal A: Cancer statistics, 2016. CA Cancer J Clin 66: 7-30, 2016.

2. Prostate Cancer Facts and Figures 2016. American Cancer Society, Inc. Atlanta, GA, 2016.

3. Dunn MW and Kazer MW: Prostate cancer overview. Semin Oncol Nurs 27: 241-250, 2011.

4. Sartor AO: Progression of metastatic castrate-resistant prostate cancer: Impact of therapeutic intervention in the post-docetaxel space. J Hematol Oncol 4: 18, 2011.

5. Skolarus TA, Wolf AMD, Erb NL, Brooks DD, Rivers BM, Underwood W III, Salner AL, Zelefsky MJ, Aragon-Ching JB, Slovin SF, et al: American Cancer Society prostate cancer survivorship care guidelines. CA Cancer J Clin 64: 225-249, 2014

6. Hieronymus H, Schultz N, Gopalan A, Carver BS, Chang MT, Xiao Y, Heguy A, Huberman K, Bernstein M, Assel M, et al: Copy number alteration burden predicts prostate cancer relapse. Proc Natl Acad Sci USA 111: 11139-11144, 2014.

7. Ferlay J, Bray F, Pisani P and Parkin DM: Globocan 2000: Cancer Incidence, Mortality and Prevalence Worldwide. IARC Press, Lyon, 2001.

8. Jemal A, Bray F, Center MM, Ferlay J, Ward E and Forman D: Global cancer statistics. CA Cancer J Clin 61: 69-90, 2011.

9. Kimura T: East meets West: Ethnic differences in prostate cancer epidemiology between East Asians and Caucasians. Chin J Cancer 31: 421-429, 2012.

10. Reinli K and Block G: Phytoestrogen content of foods--a compendium of literature values. Nutr Cancer 26: 123-148, 1996.

11. Adlercreutz H, Markkanen $\mathrm{H}$ and Watanabe S: Plasma concentrations of phyto-oestrogens in Japanese men. Lancet 342: 1209-1210, 1993.

12. Morton MS, Chan PS, Cheng C, Blacklock N, Matos-Ferreira A, Abranches-Monteiro L, Correia R, Lloyd S and Griffiths K: Lignans and isoflavonoids in plasma and prostatic fluid in men: Samples from Portugal, Hong Kong, and the United Kingdom. Prostate 32: 122-128, 1997.

13. Hwang YW, Kim SY, Jee SH, Kim YN and Nam CM: Soy food consumption and risk of prostate cancer: A meta-analysis of observational studies. Nutr Cancer 61: 598-606, 2009.

14. Van Poppel H and Tombal B: Chemoprevention of prostate cancer with nutrients and supplements. Cancer Manag Res 3: 91-100, 2011. 
15. Barnes S, Peterson TG and Coward L: Rationale for the use of genistein-containing soy matrices in chemoprevention trials for breast and prostate cancer. J Cell Biochem (Suppl) S22: 181-187, 1995.

16. Takimoto CH, Glover K, Huang X, Hayes SA, Gallot L, Quinn M Jovanovic BD, Shapiro A, Hernandez L, Goetz A, et al: Phase I pharmacokinetic and pharmacodynamic analysis of unconjugated soy isoflavones administered to individuals with cancer. Cancer Epidemiol Biomarkers Prev 12: 1213-1221, 2003.

17. Gardner CD, Oelrich B, Liu JP, Feldman D, Franke AA and Brooks JD: Prostatic soy isoflavone concentrations exceed serum levels after dietary supplementation. Prostate 69: 719-726, 2009.

18. Bloedon LT, Jeffcoat AR, Lopaczynski W, Schell MJ, Black TM, Dix KJ, Thomas BF, Albright C, Busby MG, Crowell JA, et al: Safety and pharmacokinetics of purified soy isoflavones: Singledose administration to postmenopausal women. Am J Clin Nutr 76: 1126-1137, 2002

19. Yildiz F: Phytoestrogens in functional foods. CRC Press, Boca Raton, FL, 2005. https://doi.org/10.1201/9781420027594.

20. Morito K, Hirose T, Kinjo J, Hirakawa T, Okawa M, Nohara T, Ogawa S, Inoue S, Muramatsu M and Masamune Y: Interaction of phytoestrogens with estrogen receptors alpha and beta. Biol Pharm Bull 24: 351-356, 2001.

21. Chang WY and Prins GS: Estrogen receptor-beta: Implications for the prostate gland. Prostate 40: 115-124, 1999.

22. Kumar R, Verma V, Jain A, Jain RK, Maikhuri JP and Gupta G: Synergistic chemoprotective mechanisms of dietary phytoestrogens in a select combination against prostate cancer. J Nutr Biochem 22: 723-731, 2011.

23. Wang J, Eltoum IE and Lamartiniere CA: Genistein chemoprevention of prostate cancer in TRAMP mice. J Carcinog 6: 3 2007.

24. Davis JN, Kucuk O and Sarkar FH: Expression of prostatespecific antigen is transcriptionally regulated by genistein in prostate cancer cells. Mol Carcinog 34: 91-101, 2002.

25. Bektic J, Berger AP, Pfeil K, Dobler G, Bartsch G and Klocker H: Androgen receptor regulation by physiological concentrations of the isoflavonoid genistein in androgen-dependent $\mathrm{LNCaP}$ cells is mediated by estrogen receptor beta. Eur Urol 45: 245-251, discussion 251,2004

26. Shen JC, Klein RD, Wei Q, Guan Y, Contois JH, Wang TT, Chang S and Hursting SD: Low-dose genistein induces cyclindependent kinase inhibitors and G(1) cell-cycle arrest in human prostate cancer cells. Mol Carcinog 29: 92-102, 2000.

27. Davis JN, Singh B, Bhuiyan M and Sarkar FH: Genistein-induced upregulation of p21WAF1, downregulation of cyclin B, and induction of apoptosis in prostate cancer cells. Nutr Cancer 32: 123-131, 1998.

28. Raffoul JJ, Wang Y, Kucuk O, Forman JD, Sarkar FH and Hillman GG: Genistein inhibits radiation-induced activation of NF-kappaB in prostate cancer cells promoting apoptosis and G2/M cell cycle arrest. BMC Cancer 6: 107, 2006.

29. Li Y and Sarkar FH: Down-regulation of invasion and angiogenesis-related genes identified by cDNA microarray analysis of PC3 prostate cancer cells treated with genistein. Cancer Lett 186 : $157-164,2002$

30. Guo Y, Wang S, Hoot DR and Clinton SK: Suppression of VEGFmediated autocrine and paracrine interactions between prostate cancer cells and vascular endothelial cells by soy isoflavones. J Nutr Biochem 18: 408-417, 2007.

31. Li Y, Che M, Bhagat S, Ellis KL, Kucuk O, Doerge DR, Abrams J, Cher ML and Sarkar FH: Regulation of gene expression and inhibition of experimental prostate cancer bone metastasis by dietary genistein. Neoplasia 6: 354-363, 2004

32. Zhang LL, Li L, Wu DP, Fan JH, Li X, Wu KJ, Wang XY and He DL: A novel anti-cancer effect of genistein: Reversal of epithelial mesenchymal transition in prostate cancer cells. Acta Pharmacol Sin 29: 1060-1068, 2008.

33. Kumi-Diaka JK, Hassanhi M, Merchant $\mathrm{K}$ and Horman V: Influence of genistein isoflavone on matrix metalloproteinase-2 expression in prostate cancer cells. J Med Food 9: 491-497, 2006.

34. Kazi A, Daniel KG, Smith DM, Kumar NB and Dou QP Inhibition of the proteasome activity, a novel mechanism associated with the tumor cell apoptosis-inducing ability of genistein. Biochem Pharmacol 66: 965-976, 2003.

35. Kumi-Diaka J, Sanderson NA and Hall A: The mediating role of caspase-3 protease in the intracellular mechanism of genisteininduced apoptosis in human prostatic carcinoma cell lines, DU145 and LNCaP. Biol Cell 92: 595-604, 2000.
36. Lee J, Ju J, Park S, Hong SJ and Yoon S: Inhibition of IGF-1 signaling by genistein: Modulation of E-cadherin expression and downregulation of $\beta$-catenin signaling in hormone refractory PC-3 prostate cancer cells. Nutr Cancer 64: 153-162, 2012.

37. Xu L and Bergan RC: Genistein inhibits matrix metalloproteinase type 2 activation and prostate cancer cell invasion by blocking the transforming growth factor beta-mediated activation of mitogenactivated protein kinase-activated protein kinase $2-27-\mathrm{kDa}$ heat shock protein pathway. Mol Pharmacol 70: 869-877, 2006.

38. Davis JN, Kucuk O and Sarkar FH: Genistein inhibits NF-kappaB activation in prostate cancer cells. Nutr Cancer 35: 167-174, 1999.

39. Li Y and Sarkar FH: Inhibition of nuclear factor kappaB activation in PC3 cells by genistein is mediated via Akt signaling pathway. Clin Cancer Res 8: 2369-2377, 2002.

40. Akiyama T, Ishida J, Nakagawa S, Ogawara H, Watanabe S, Itoh N, Shibuya M and Fukami Y: Genistein, a specific inhibitor of tyrosine-specific protein kinases. J Biol Chem 262: 5592-5595, 1987.

41. Park CE, Yun H, Lee EB, Min BI, Bae H, Choe W, Kang I, Kim SS and Ha J: The antioxidant effects of genistein are associated with AMP-activated protein kinase activation and PTEN induction in prostate cancer cells. J Med Food 13: 815-820, 2010

42. Raschke M, Rowland IR, Magee PJ and Pool-Zobel BL: Genistein protects prostate cells against hydrogen peroxide-induced DNA damage and induces expression of genes involved in the defence against oxidative stress. Carcinogenesis 27: 2322-2330, 2006.

43. Swami S, Krishnan AV, Moreno J, Bhattacharyya RS, Gardner C, Brooks JD, Peehl DM and Feldman D: Inhibition of prostaglandin synthesis and actions by genistein in human prostate cancer cells and by soy isoflavones in prostate cancer patients. Int J Cancer 124: 2050-2059, 2009.

44. Adjakly M, Bosviel R, Rabiau N, Boiteux JP, Bignon YJ, Guy L and Bernard-Gallon D: DNA methylation and soy phytoestrogens: Quantitative study in DU-145 and PC-3 human prostate cancer cell lines. Epigenomics 3: 795-803, 2011.

45. Vardi A, Bosviel R, Rabiau N, Adjakly M, Satih S, Dechelotte P, Boiteux JP, Fontana L, Bignon YJ, Guy L, et al: Soy phytoestrogens modify DNA methylation of GSTP1, RASSF1A, EPH2 and BRCA1 promoter in prostate cancer cells. In Vivo 24: 393-400, 2010.

46. Fang MZ, Chen D, Sun Y, Jin Z, Christman JK and Yang C: Reversal of hypermethylation and reactivation of $p 16^{I N K 4 a}$, RARbeta, and MGMT genes by genistein and other isoflavones from soy. Clin Cancer Res 11: 7033-7041, 2005.

47. Majid S, Dar AA, Shahryari V, Hirata H, Ahmad A, Saini S, Tanaka Y, Dahiya AV and Dahiya R: Genistein reverses hypermethylation and induces active histone modifications in tumor suppressor gene B-Cell translocation gene 3 in prostate cancer. Cancer 116: 66-76, 2010.

48. Kikuno N, Shiina H, Urakami S, Kawamoto K, Hirata H, Tanaka Y, Majid S, Igawa M and Dahiya R: Genistein mediated histone acetylation and demethylation activates tumor suppressor genes in prostate cancer cells. Int J Cancer 123: 552-560, 2008.

49. Li Y, Kong D, Ahmad A, Bao B, Dyson G and Sarkar FH: Epigenetic deregulation of miR-29a and miR-1256 by isoflavone contributes to the inhibition of prostate cancer cell growth and invasion. Epigenetics 7: 940-949, 2012.

50. Rabiau N, Trraf HK, Adjakly M, Bosviel R, Guy L, Fontana L, Bignon YJ and Bernard-Gallon DJ: miRNAs differentially expressed in prostate cancer cell lines after soy treatment. In Vivo 25: 917-921, 2011.

51. Chen Y, Zaman MS, Deng G, Majid S, Saini S, Liu J, Tanaka Y and Dahiya R: MicroRNAs 221/222 and genistein-mediated regulation of ARHI tumor suppressor gene in prostate cancer. Cancer Prev Res (Phila) 4: 76-86, 2011.

52. Chiyomaru T, Yamamura S, Fukuhara S, Hidaka H, Majid S, Saini S, Arora S, Deng G, Shahryari V, Chang I, et al: Genistein up-regulates tumor suppressor microRNA-574-3p in prostate cancer. PLoS One 8: e58929, 2013.

53. Hillman GG, Forman JD, Kucuk O, Yudelev M, Maughan RL, Rubio J, Layer A, Tekyi-Mensah S, Abrams J and Sarkar FH: Genistein potentiates the radiation effect on prostate carcinoma cells. Clin Cancer Res 7: 382-390, 2001

54. Li Y, Kucuk O, Hussain M, Abrams J, Cher ML and Sarkar FH: Antitumor and antimetastatic activities of docetaxel are enhanced by genistein through regulation of osteoprotegerin/receptor activator of nuclear factor-kappaB (RANK)/RANK ligand/ MMP-9 signaling in prostate cancer. Cancer Res 66: 4816-4825, 2006. 
55. Spagnuolo C, Russo GL, Orhan IE, Habtemariam S, Daglia M, Sureda A, Nabavi SF, Devi KP, Loizzo MR, Tundis R, et al: Genistein and cancer: Current status, challenges, and future directions. Adv Nutr 6: 408-419, 2015.

56. Katoh M: Network of WNT and other regulatory signaling cascades in pluripotent stem cells and cancer stem cells. Curr Pharm Biotechnol 12: 160-170, 2011.

57. Mori R, Wang Q, Danenberg KD, Pinski JK and Danenberg PV: Both beta-actin and GAPDH are useful reference genes for normalization of quantitative RT-PCR in human FFPE tissue samples of prostate cancer. Prostate 68: 1555-1560, 2008.

58. Reich M, Liefeld T, Gould J, Lerner J, Tamayo P and Mesirov JP: GenePattern 2.0. Nat Genet 38: 500-501, 2006.

59. Eisen MB, Spellman PT, Brown PO and Botstein D: Cluster analysis and display of genome-wide expression patterns. Proc Natl Acad Sci USA 95: 14863-14868, 1998

60. Saldanha AJ: Java Treeview - extensible visualization of microarray data. Bioinformatics 20: 3246-3248, 2004.

61. Barfield RT, Kilaru V, Smith AK and Conneely KN: CpGassoc: An $\mathrm{R}$ function for analysis of DNA methylation microarray data. Bioinformatics 28: 1280-1281, 2012.

62. http://www.qiagen.com/ingenuity: Qiagen's Ingenuity Pathway Analysis.

63. Dennis G Jr, Sherman BT, Hosack DA, Yang J, Gao W, Lane HC and Lempicki RA: DAVID: Database for Annotation, Visualization, and Integrated Discovery. Genome Biol 4: 3, 2003

64. Wang $\mathrm{Z}$ and Chen $\mathrm{H}$ : Genistein increases gene expression by demethylation of WNT5a promoter in colon cancer cell line SW1116. Anticancer Res 30: 4537-4545, 2010.

65. Gao BN and Gilman AG: Cloning and expression of a widely distributed (type IV) adenylyl cyclase. Proc Natl Acad Sci USA 88: 10178-10182, 1991.

66. Brikun I, Nusskern D, Gillen D, Lynn A, Murtagh D, Feczko J, Nelson WG and Freije D: A panel of DNA methylation markers reveals extensive methylation in histologically benign prostate biopsy cores from cancer patients. Biomark Res 2: 25, 2014.

67 Monti E, Bonten E, D'Azzo A, Bresciani R, Venerando B Borsani G, Schauer R and Tettamanti G: Sialidases in vertebrates: A family of enzymes tailored for several cell functions. Adv Carbohydr Chem Biochem 64: 403-479, 2010

68. Uemura T, Shiozaki K, Yamaguchi K, Miyazaki S, Satomi S, Kato K, Sakuraba H and Miyagi T: Contribution of sialidase NEU1 to suppression of metastasis of human colon cancer cells through desialylation of integrin beta4. Oncogene 28: 1218-1229, 2009.

69. Kato T, Wang Y, Yamaguchi K, Milner CM, Shineha R, Satomi S and Miyagi T: Overexpressing of lysosomal-type sialidase leads to suppression of metastasis associated with reversion of malignant phenotype in murine B16 melanoma cells. Int J Cancer 92: 797-804, 2001

70. Chang S, He S, Qiu G, Lu J, Wang J, Liu J, Fan L, Zhao W and Che X: MicroRNA-125b promotes invasion and metastasis of gastric cancer by targeting STARD13 and NEU1. Tumour Biol 37: 12141-12151,2016.

71. Haxho F, Neufeld RJ and Szewczuk MR: Neuraminidase-1: A novel therapeutic target in multistage tumorigenesis. Oncotarget 7: 40860-40881, 2016.

72. Liu L, Chen X, Wang Y, Qu Z, Lu Q, Zhao J, Yan X, Zhang H and Zhou Y: Notch3 is important for TGF- $\beta$-induced epithelialmesenchymal transition in non-small cell lung cancer bone metastasis by regulating ZEB-1. Cancer Gene Ther 21: 364-372, 2014.

73. Danza G, Di Serio C, Ambrosio MR, Sturli N, Lonetto G, Rosati F, Rocca BJ, Ventimiglia G, del Vecchio MT, Prudovsky I, et al: Notch 3 is activated by chronic hypoxia and contributes to the progression of human prostate cancer. Int $\mathbf{J}$ Cancer 133 2577-2586, 2013

74. Terada N, Shiraishi T, Zeng Y, Aw-Yong KM, Mooney SM, Liu Z, Takahashi S, Luo J, Lupold SE, Kulkarni P, et al: Correlation of Sprouty1 and Jagged1 with aggressive prostate cancer cells with different sensitivities to androgen deprivation. J Cell Biochem 115: 1505-1515, 2014
75. Pedrosa AR, Graca JL, Carvalho S, Peleteiro MC, Duarte A and Trindade A: Notch signaling dynamics in the adult healthy prostate and in prostatic tumor development. Prostate 76: 80-96, 2016.

76. Pedrosa AR, Trindade A, Carvalho C, Graça J, Carvalho S, Peleteiro MC, Adams RH and Duarte A: Endothelial Jagged1 promotes solid tumor growth through both pro-angiogenic and angiocrine functions. Oncotarget 6: 24404-24423, 2015.

77. Danza G, Di Serio C, Rosati F, Lonetto G, Sturli N, Kacer D, Pennella A, Ventimiglia G, Barucci R, Piscazzi A, et al: Notch signaling modulates hypoxia-induced neuroendocrine differentiation of human prostate cancer cells. Mol Cancer Res 10 230-238, 2012.

78. Rampias T, Vgenopoulou P, Avgeris M, Polyzos A, Stravodimos K, Valavanis C, Scorilas A and Klinakis A: A new tumor suppressor role for the Notch pathway in bladder cancer. Nat Med 20: 1199-1205, 2014.

79. Hernandez Tejada FN, Galvez Silva JR and Zweidler-McKay PA The challenge of targeting notch in hematologic malignancies. Front Pediatr 2: 54, 2014.

80. Giachino C, Boulay JL, Ivanek R, Alvarado A, Tostado C, Lugert S, Tchorz J, Coban M, Mariani L, Bettler B, et al: A tumor suppressor function for Notch signaling in forebrain tumor subtypes. Cancer Cell 28: 730-742, 2015.

81. Jaskula-Sztul R, Eide J, Tesfazghi S, Dammalapati A, Harrison AD, Yu XM, Scheinebeck C, Winston-McPherson G, Kupcho KR, Robers MB, et al: Tumor-suppressor role of Notch3 in medullary thyroid carcinoma revealed by genetic and pharmacological induction. Mol Cancer Ther 14: 499-512, 2015.

82. Sriuranpong V, Borges MW, Ravi RK, Arnold DR, Nelkin BD, Baylin SB and Ball DW: Notch signaling induces cell cycle arrest in small cell lung cancer cells. Cancer Res 61: 3200-3205, 2001.

83. Liu YL, Zhang GQ, Yang Y, Zhang CY, Fu RX and Yang YM: Genistein induces $\mathrm{G} 2 / \mathrm{M}$ arrest in gastric cancer cells by increasing the tumor suppressor PTEN expression. Nutr Cancer 65: 1034-1041, 2013.

84. Su SJ, Yeh TM, Chuang WJ, Ho CL, Chang KL, Cheng HL, Liu HS, Cheng HL, Hsu PY and Chow NH: The novel targets for anti-angiogenesis of genistein on human cancer cells. Biochem Pharmacol 69: 307-318, 2005.

85. Jagadeesh S, Kyo S and Banerjee PP: Genistein represses telomerase activity via both transcriptional and posttranslational mechanisms in human prostate cancer cells. Cancer Res 66: 2107-2115, 2006.

86. Mahmoud AM, Al-Alem U, Ali MM and Bosland MC: Genistein increases estrogen receptor beta expression in prostate cancer via reducing its promoter methylation. J Steroid Biochem Mol Biol 152: 62-75, 2015.

87. Whirledge S, Senbanjo LT and Cidlowski JA: Genistein disrupts glucocorticoid receptor signaling in human uterine endometrial Ishikawa cells. Environ Health Perspect 123: 80-87, 2015.

88. Bhamre S, Sahoo D, Tibshirani R, Dill DL and Brooks JD: Gene expression changes induced by genistein in the prostate cancer cell line LNCaP. Open Prostate Cancer J 3: 86-98, 2010.

89. Ghaemi A, Soleimanjahi H, Razeghi S, Gorji A, Tabaraei A, Moradi A, Alizadeh A and Vakili MA: Genistein induces a protective immunomodulatory effect in a mouse model of cervical cancer. Iran J Immunol 9: 119-127, 2012.

90. Korde LA, Wu AH, Fears T, Nomura AM, West DW, Kolonel LN, Pike MC, Hoover RN and Ziegler RG: Childhood soy intake and breast cancer risk in Asian American women. Cancer Epidemiol Biomarkers Prev 18: 1050-1059, 2009.

91. Lee SA, Shu XO, Li H, Yang G, Cai H, Wen W, Ji BT, Gao J, Gao YT and Zheng W: Adolescent and adult soy food intake and breast cancer risk: Results from the Shanghai Women's Health Study. Am J Clin Nutr 89: 1920-1926, 2009. 